\begin{abstract}
ARTICULO
Revista Derecho - Año 3 edicion $561-78$

Web: http://revistas.unap.edu.pe/rd E-mail.com: revistaderecho@unap.edu.pe ISSN 2313-6944

\section{LA CONSIDERACIÓN JURIDICA DEL ADULTO MAYOR Y SU PROBLEMÁTICA EN EL PERU}

\author{
Jose Alfredo Pineda Gonzales*
}

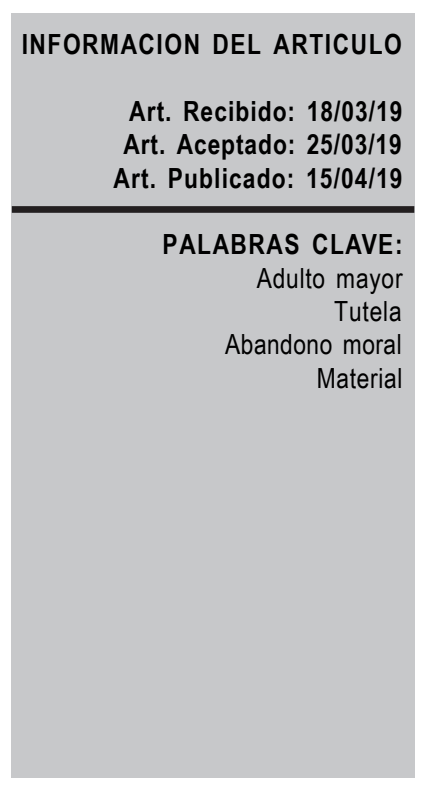

RESUMEN
Se trata de una investigación cuya temática aborda la problemática de
desamparo y desprotección en que se encuentra el adulto mayor en
nuestro país y el análisis de la legislación para verificar la inexistencia de
una institución jurídica que bajo el ámbito del derecho tutelar le pue-
da brindar protección jurídica integral, previniendo y resolviendo si-
tuaciones de abandono moral y material, maltrato y exposición de
personas en riesgo e indigencia. El planteamiento del problema se
traduce en la formulación de la siguiente pregunta: ¿Se ha establecido
una idónea institución de protección jurídica del adulto mayor en
nuestro país? El objetivo general fue: Analizar la protección jurídica
del adulto mayor en la legislación nacional. Para lograr el objetivo
propuesto se realizaron actividades de análisis documental de la base
teórica, interpretación de normas jurídicas y análisis de casos. Los
resultados nos ha permitido concluir que no existe una protección
jurídica suficiente para el adulto mayor por parte del estado y la comu-
nidad, basada en una institución jurídica específica e idónea, y frente a
ello proponemos a la tutela como institución dirigida a ese propósito.

*Abogado. Magister en Derecho Público. Doctor en Derecho. Universidad Nacional del Altiplano de Puno. Perú.japineda@unap.edu.pe 


\section{THE LEGAL CONSIDERATION OF THE ADULT MAJOR AND ITS PROBLEMS IN PERU}

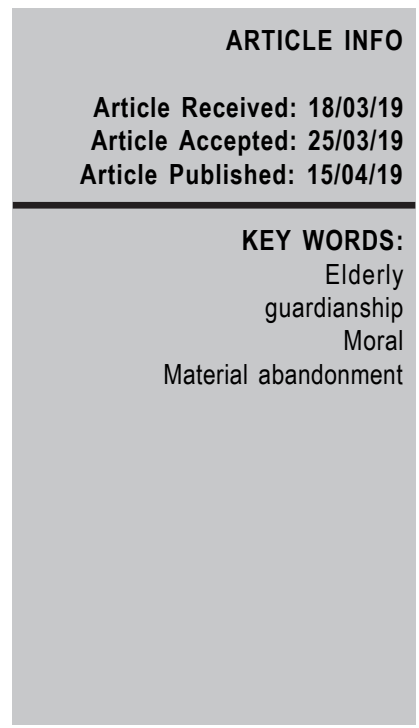

\section{ABSTRACT}

This is an investigation thatpresents the problem of abandonment and vulnerability in which the elderly are in our country and the analysis of the legislation to verify the absence of a legal institution that, under the scope of guardianship, can provide comprehensive legal protection in order to prevent and solve situations of moral and material abandonment, abuse and exposure of people at risk and destitution. The problem statement results in the following question: Has a suitable institution of legal protection for the elderly in our country been established? The general objective was: To analyze the legal protection of the elderly in the national legislation. To achieve our objective, documentary analysis activities of the theoretical basis, interpretation of legal norms and case analysis were conducted. The results allow us to conclude that there is not enough legal protection from the state and the community, based on a specific and suitable legal institution, for the elderly. To address this situation we propose the guardianship as an institution aimed at that purpose.

62 Revista Derecho - 5 (2019) 


\section{INTRODUCCION}

Para comenzar el estudio del tema del adulto mayor en el Perú, es necesario apreciar los diversos problemas que este sensible sector de la población atraviesa. Estas, a manera de contexto, se resumen en los siguientes aspectos:

a) La situación de las precarias pensiones de los cesantes y jubilados de las leyes 20530 y 19990, que generan con frecuencia marchas, protestas, plantones, huelgas y otros mecanismos de reclamo frente al Estado.

b) La situación de abandono e indigencia de muchos adultos mayores que nos permite visualizar casi a diario en la mayoría de ciudades del país este drama humano.

c) La situación de violencia y abandono de los adultos mayores por sus hijos que llegan inclusive no solamente a ser caso de tema mediático sino que además de procesos judiciales, en los que los ancianos pierden sus propiedades y posesiones por acción de los hijos.

d) La situación de marginación de los ancianos para quienes no existe posibilidad de empleo, de políticas de atención, esparcimiento y cultura por parte de la sociedad civil y el Estado relegándolos a una suerte de muerte civil.
Levantar un diagnóstico de la situación social y jurídica del adulto mayor no es una cuestión difícil, en realidad a diario enfrentamos cuadros dramáticos de adultos mayores mendigando para poder sobrevivir, otros viviendo en la vía pública sometidos a los vejámenes y la indiferencia de la gente. El problema entonces no es virtual sino fáctico y de diaria constatación.

En ese contexto cabe reflexionar sobre los factores que conllevan a este estado de cosas. Un análisis desde el Derecho nos puede permitir entender de mejor forma esta problemática; así el análisis de la materia, desde la propia naturaleza jurídica del adulto mayor hasta el análisis propiamente de la legislación deben apuntar a encontrar respuestas que permitan establecer coordenadas que articulen una mejor legislación, más idónea, más pertinente y de mayor efectividad.

\section{GENERALIDADES}

Se define a un adulto mayor como aquella persona de 60 años o más-edad. ${ }^{1}$ La expresión adulto mayor ha reemplazado otros términos comunes tales como viejo, anciano, persona de edad o persona de la tercera edad. Corresponde a la última etapa de la vida del hombre. (Zapata Farias, 2001 p. 190)

Definición establecida en la Asamblea Internacional sobre el Envejecimiento de Viena de 1982. 
En tanto se alude a la última etapa de la vida, la vejez ha sido asociada al desvalimiento y a la inutilidad y ello ha dado origen a instituciones orientadas a dar ayuda desde una postura básicamente asistencial. Así el adulto mayor tiene la tendencia a estancarse, tener la sensación de inutilidad, sentirse desgraciados y rígidos (Belsky, 1996, p. 27)

El tema de la tercera edad es un tema invisible (Armijo, 2009, p. 388), muy a pesar de que este sector de la población ha sido considerada dentro de la denominada población vulnerable $\mathrm{e}^{2}$ por ello debería merecer la atencipón especial de la sociedad y del Estado. Tanto más que los estudios globales sobre demografía dan cuenta que el mundo se encuentra en un franco proceso de envejecimiento. Las estadísticas, sin duda nos pueden ofrecer un panorama más amplio para entender mejor la situación.

Entre 2015 y 2050, el porcentaje de los habitantes del planeta mayores de 60 años casi se duplicará, pasando del $12 \%$ al $22 \%$. Para 2020, el número de personas de 60 años o más será superior al de niños menores de cinco años. (OMS, 2019)
Este panorama también se refleja en el ámbito nacional, así el Instituto Nacional de Estadística e Informática señala que la población del Perú en el año 2018 son menores de 15 años 27 de cada 100 habitantes y la población adulta mayor aumenta de $5.7 \%$ en el año 1950 a 10.4\% en el año 2018. (INEI, 2018), por lo tanto nuestra sociedad también envejece. Ese legado de tendencias pasadas no se puede alterar, detener o modificar, por lo que constituye una alerta para la sociedad y el Estado.

En esa perspectiva se ha elaborado por parte del Ministerio de la Mujer y poblaciones vulnerables el «Plan Nacional para Personas Adultas Mayores 2013-2017», documento que presenta los enfoques de derechos humanos, de igualdad de género, de interculturalidad, así como el enfoque intergeneracional. En el plano de las políticas públicas se aprecia entonces una preocupación, por lo menos en la dimensión teórica, su correlato en la propia realidad refleja una situación distinta. Pero la mayor preocupación que ponemos en evidencia debe darse en el ámbito de la legislación, y como se apreciará líneas adelante, en ese ámbito no existe una similar preocupación.

100 Reglas de Brasilia sobre acceso a la justicia de personas en condición de vulnerabilidad

Plan Nacional para las personas adulto mayores 2013-2017 fue aprobado por D.S. N 002-3013-MIMP

64 Revista Derecho-5 (2019) 
III. CONSIDERACION JURÍDICA DEL ADULTO MAYOR

La temática de la vida, su origen y desarrollo ha sido motivo de preocupación de filósofos, teólogos y científicos hace alrededor de veinticuatro siglos. Uno de los testimonios más admirables acerca de esta problemática lo da Aristóteles (siglo IV A.C.) El Filósofo se planteó una serie de cuestiones teóricas acerca de la vida y los seres vivos. Para empezar ¿qué es la vida? Un cadáver tiene los mismos órganos y tejidos que un cuerpo vivo. ¿Qué tiene el segundo, que le falte al primero? (Gonzales, 1996, p. 23)

Sin duda el concepto de la vida misma puede tener diversas explicaciones y sentidos, dependiendo de la perspectiva de análisis en la que nos enfrasquemos; sin embargo, la muerte también resulta una preocupación permanente, y si bien no esta en discusión la posibilidad de prolongar la vida en forma indefinida, lo está sí prolongar la existencia hasta límites cada vez más precisos. Peor en la discusión de la vida y la muerte, encontramos la temática de la existencia misma en su desarrollo entre las variables antes indicadas: Vida y muerte.

Desde determinada perspectiva, las etapas de la vida que encontramos en ambos extremos están la niñez, la adolescencia, la juventud, la adultez y la senectud. Esta última etapa de la vida es materia de nuestra preocupación jurídica y social.

Se encuentra claro que la determinación y status jurídico de la niñez, de la adolescencia y de la adultez tienen en el derecho un tratamiento diferenciado basado en que siendo etapas diferentes de la vida humana, merecen desde luego un tratamiento jurídico diferente. Precisamente la categoría del sujeto de derecho es utilizada para referirse a las distintas fases de la vida del ser humano. (Varsi, 2014, p. 95)

Así, relacionar al sujeto de derecho con una categoría jurídica es tender a una clasificación, una taxonomía, una tipología que permita diferenciar estados biológicos o sociales a fin de ofrecerles la mejor protección. (Varsi, 2014, p.101)

La clasificación en que se le atribuya a la persona puede cambiar, así lo señala la teoría de la transformación, así el concebido, una vez que nace, se transforma en una persona natural, ý esta va adquiriendo (según los estadíos de desarrollo sicosomático) la de niño, adolescente y luego adulto. No puede sin embargo, revertir dicha clasificación jurídica (así una persona natural no puede volver a ser concebido (teoría de la reversión).

La persona natural, que es el estatus jurídico en el que ubicamos al

Revista Derecho - 5 (2019) 65 
adulto mayor, es el ser humano entre su nacimiento y su muerte, con personalidad jurídica, es decir, con capacidad de tener derechos y obligaciones (Rubio, 2001, p. 227)

El caso del adulto mayor o anciano, que corresponde a la etapa de la senectud o ancianidad, se ubica también en esta taxonomía, y refleja en la doctrina un tratamiento bastante limitado, por cuanto mayormente se considera al anciano como un adulto más, al que eventualmente hay que brindarle algunas consideraciones que más bien tiene su punto de partida en las consideraciones sociales de la cortesía, las buenas maneras, o acaso el respeto mismo, sin que se haya realizado esfuerzos significativos para ubicar esta etapa de la vida en un espacio que merezca un tratamiento jurídico especial, en la búsqueda permanente de revivificar su dignidad de quienes se encuentran en el epílogo de la vida.

En esa línea, no obstante, encontramos a los sujetos de derecho especiales que son aquellos llamados débiles jurídicos, personas vulnerables ${ }^{4}(\ldots)$ como ancianos. Frente a ello, la solución nunca podrá ser la exclusión sino la rehabilitación y la integración. (Dueñas, 2009, p. 135) Así, los débiles jurídicos al no poder valerse por si mismos requie- ren de un tratamiento orgánico y uniforme dada su incapacidad, de forma tal que se establezca en ejecución práctica del principio pro homine y debilis los medios de resguardo, dejando de lado su anterior categoría de nom sujet de droit. (Varsi, 2014, p. 105) Asi dentro de los sujetos de derecho individuales encontramos al concebido y a la persona natural, y dentro de esta ultima precisamente al adulto mayor.

Esta perspectiva de análisis, sin embargo, respecto del adulto mayor, colisiona con una legislación que no recoge estos principios, pues no establece para el caso un estatuto jurídico distinto y tuitivo. La niñez y la adolescencia tienen precisamente para este sector de la población un Código que articula regulaciones sustantivas y procesales, y si bien el adulto mayor tiene una ley especial, no deja de ser aun una legislación insuficiente como veremos en el análisis correspondiente.

\section{LA PROTECCIÓN JURÍDICA DEL ADULTO MAYOR}

\section{a) La Legislación supranacional.}

El sistema jurídico de un país se delimita en función del principio de jerarquía normativa, que alude a varios criterios para determinar que una norma es superior a otra, así se sostiene en

Las 100 Reglas de Brasilia considera a los ancianos como población en situación de vulnerabilidad.

66 Revista Derecho - 5(2019) 
función de la superioridad del órgano que lo produce (Ruiz, 1988, p. 137), pero existiendo otros criterios, no cabe duda que esa es la forma en que el ordenamiento jurídico se estructura, en base a una jerarquización. En ese contexto, si bien la legislación supranacional -en estricto- no correspondería al ordenamiento jurídico nacional, ${ }^{5}$ la Carta Política establece en su artículo 51 que los tratados de Derechos Humanos tambien forma parte de la legislación interna, aunque lo correcto sería hablar de derechos fundamentales (Montoya, y Feijoo, 2015, p. 337)

$\mathrm{Al}$ respecto el Tribunal Constitucional, en reiteradas sentencias tambien se ha referido al tema, los tratados son Derecho válido, eficaz y, en consecuencia, inmediatamente aplicable al interior del estado, ${ }^{6}$ en un plano más concreto, los derechos humanos enunciados en los tratados que conforman nuestro ordenamiento vinculan a los poderes públicos y, dentro de ellos, ciertamente, al legislador. ${ }^{7}$

En este bloque, encontramos a diversos instrumentos de los derechos humanos que aluden a la condición del adulto mayor, uno de los antecedentes es el Plan de Acción Internacional de Viena sobre el Envejecimiento, en esa propuesta se trató la situación del adulto mayor y se concluyó en la necesidad de iniciar un programa internacional de acción encaminado a garantizar la seguridad social y la economía de las personas de edad, (Mora, 2010) igualmente una pretendida Declaración de los Derechos Humanos de las personas de edad avanzada, sin embargo la propuesta no se concretizó por oposición de algunos países.

En el análisis global, los instrumentos sobre Derechos Humanos sólo realizan una mención implícita sobre el adulto mayor a través del reconocimiento del derecho a la igualdad (proscribiendo la discriminación), a la salud y a la seguridad social. El centrar a la ancianidad en los derechos económicos y sociales, o respecto de ancianos vulnerables ha sido la tendencia general en el ámbito internacional. (Barcia, 2014, p. 71)

Fue con la Convención Americana de Derechos Humanos que se introdujo una normativa específica relacionada al adulto mayor, así, mediante el Protocolo Adicional a la Convención Americana en materia de Derechos Económicos, Sociales y Culturales, Protocolo de San Salvador, ${ }^{8}$ así mediante el artículo 17 se establece que toda perso-

\footnotetext{
El artículo 51 de la Constitución Política del Estado establece la jerarquización del ordenamiento jurídico nacional.

Sentencia recaída en el expediente No. 5854-2005-PA/TC.

Sentencia recaída en el expediente No. 0025- 2005-PI/TC.

El Protocolo adicional a la Convención Americana en Derechos Económicos, Sociales y Culturales fue suscrito por el Estado Peruano en 1988 y se ratificó en 1995.
} 
na tiene derechos a protección especialmente durante su ancianidad y compromete la acción del Estado para que los adulto mayores que no puedan atender sus necesidades de alimentación y atención médica lo reciban del Estado, de igual forma el establecimiento de programas laborales adecuados, y generar organizaciones sociales para mejorar su calidad de vida. El Protocolo por tanto es vinculante para el Estado Peruano al formar parte del bloque de constitucionalidad.

No obstante la existencia del Protocolo, se requería sin duda de un instrumento internacional de las personas adultas mayores, la misma que desde la mirada de los Derechos Humanos pudiera acometer una mayor protección y promoción. Así, el 15 de junio del año 2015, en la 45 Sesión de la Asamblea de la Organización de Estados Americanos (OEA) y en consonancia con el día mundial de la concientización sobre la violencia con los adultos mayores se aprobó la Convención Interamericana sobre derechos de las Personas Mayores. Si bien la denominación de personas mayores no responde a la tendencia internacional de denominar adultos mayores, este cuerpo normativo viene a llenar un vacío existente.

Como lo señala la propia Convención, su objeto es promover, proteger y garantizar el reconocimiento y el pleno goce y ejercicio, en condiciones de igualdad, de todos los derechos humanos y libertades fundamentales de la persona mayor (adulto mayor), a fin de contribuir a su plena inclusión, integración y participación en la sociedad.

La promoción y defensa de sus derechos humanos y libertades fundamentales conjuntamente con la valorización de la persona adulta mayor, su papel en la sociedad y contribución al desarrollo, así como el respeto a su dignidad, configuran sus principales principios. La norma en cuestión ha servido de inspiración para el legislador nacional para desarrollar el sistema de apoyos y salvaguardas en el Decreto Legislativo $1384^{\circ}$, también para adecuar algunas políticas de trabajo del Poder Judicial y permitir un acceso a la justicia en forma real y adecuada implementando un sistema de alertas para imprimir mayor tuitividad.

La Convención viene a llenar un vacío, la comunidad internacional demoró en su elaboración pero con él generó el imperativo de su suscripción y su incorporación en el derecho interno de cada país. En este caso, la Convención aún no ha sido ratificada por el Estado Peruano.

El Decreto Legislativo $N^{\circ} 1384$ publicada el 4 de setiembre del 2018 regula y reconoce la capacidad jurídica de las personas con discapacidad en igualdad de condiciones de igualdad.

68 Revista Derecho - 5 (2019) 
Es importante también agregar, en esta parte, que la normativa internacional incorporada al derecho interno del Perú se complementa con las resoluciones vinculantes de la Corte Interamericana de Derechos Humanos, así en alusión a los adultos mayores, la Corte se pronunció en los casos Cinco pensionistas vs. Perú (2003) y Acevedo Buendía y otros vs. Perú (2009)..$^{10}$ En tales resoluciones la Corte interpretó el derecho de propiedad en un sentido que abarcaba la prohibición de modificar la prestación de jubilación mediante enmiendas a las regulaciones internas con posterioridad a la fecha del retiro, jubilación o cese.

Como se puede apreciar las regulaciones contenidas en los instrumentos de derechos humanos y aún, las decisiones de los Tribunales de Justicia internacionales sólo desarrollan aspectos referidos a la protección del adulto mayor frente a la discriminación, atención en su salud y a un adecuado sistema de pensiones. No resulta por tanto la protección particular que se espera, pues sólo ocupa algunos aspectos, dado que los adultos mayores gozan de todos los derechos que se les reconoce a las persona adultas, pero es cierto que la singularidad del adulto mayor le hace destinatario de normas muchos más tuitivas.

\section{b) La Constitución Política del Es- tado.}

Se encuentra sumamente claro que la persona adulta mayor se encuentra comprendida dentro del grupo poblacional considerado en estado de vulnerabilidad, siendo así su consideración jurídica debería merecer una normatividad constitucional clara y concreta. Sin embargo ello no acontece en nuestra realidad, situación que resulta muy similar a la de otros países, sobre todo de nuestra órbita latinoamericana, como veremos más adelante.

En el Perú, la Constitución Política del Estado establece una protección expresa para el adulto mayor en situación de abandono, pero no establece normas que aludan a la protección cuando no se encuentra en la condición de abandonado. Así, en el capítulo segundo de la Carta Política: de los derechos sociales y económicos, artículo cuarto, se consagra «la comunidad y el Estado protegen especialmente al niño, al adolescente, a la madre y al anciano en situación de abandono.» Del precepto antes transcrito se desprende que la situación de abandono en que se encuentren el niño, el adolescente, la madre y el anciano es motivo de especial protección por parte de la comunidad y del Estado. Sobre este particular debe

10 Sentencia de la Corte Interamericana de Derechos Humanos, «Caso de 'cinco pensionistas' vs. Perú (méritos, reparaciones y costas), del 28 de febrero del 2003", Series C, núm. 98, y sentencia del «Caso Acevedo Buendía y otros ('Cesantes y Jubilados de la Contraloría') vs. Perú (objeciones preliminares, méritos, costas y reparaciones), del 1 de julio de 2009", Series C, núm. 198. 
precisarse que en efecto, la situación de abandono en que se encuentra el niño y el adolescente recibe en la legislación nacional un tratamiento especial a través del Código Civil y a través del Código de los Niños y Adolescentes, en esta última norma, a través del capítulo noveno, que inicialmente faculta al Ministerio de la mujer y Poblaciones Vulnerables una diversidad de medidas destinadas a proteger a los niños y adolescentes en presunto estado de abandono (Riesgo o desprotección familiar), encontrándose en la actualidad dicha facultad en manos de las Unidades de Protección Especial y del Poder Judicial a través de los Juzgados Especializados de Familia. Sin embargo no existe una normativa ordinaria que desarrolle en forma concreta la situación de abandono ${ }^{11}$ del adulto mayor como veremos más adelante.

Es cierto que los derechos que se le atribuyen a la persona adulta, en general, también le corresponde al adulto mayor, sin embargo -como ya se dijola singularidad de la condición psicosomática del adulto mayor exige una consideración jurídica especial, y la norma de la que debe partir esa consideración debe ser precisamente la Constitución. Pues considerar que sólo el adulto mayor en estado de abandono debe merecer una protección constitucional especial es reducir la perspectiva tuitiva, que sólo advierte la generalidad y no la singularidad, se protege a la persona no por consideración de la vejez como significante principal sino en su condición de persona.

En ese sentido corresponde la modificación de la protección del adulto mayor lleve una fórmula abstracta, es decir, que la protección sea al adulto mayor en general y no especifica, que solamente aluda a aquel que se encuentre en estado de abandono. El caso concreto de la Constitución de la República del Ecuador ${ }^{12}$ puede resultar un referente importante al respecto. A su vez, la Constitución Colombiana ${ }^{13}$ también ofrece una normatividad importante, con un añadido sobre la participación de la familia en la protección, conjuntamente con el Estado y la sociedad. En forma similar, la Constitución Venezo-

11 De acuerdo al Glosario de términos contenido en el D.S. 007-2018-MIMP la situación de abandono se entiende como la falta de acción deliberada o no, por parte de una persona o institución responsable de la protección de la persona adulta mayor, para atender de manera integral sus necesidades, poniendo en peligro su vida o su integridad física, psíquica o moral.

12 Art. 35 de la Constitución de Ecuador: «Las personas adultas mayores, niñas, niños y adolescentes, mujeres embarazadas, personas con discapacidad, personas privadas de libertad y quienes adolezcan de enfermedades catastróficas o de alta complejidad, recibirán atención prioritaria y especializada en los ámbitos público y privado

13 Art. 46 de la Constitución de Colombia: «El Estado, la sociedad y la familia concurrirán para la protección y la asistencia de las personas de la tercera edad y promoveran su integración a la vida activa y comunitaria».

70 Revista Derecho - 5(2019) 
lana ${ }^{14}$ también reconoce el rol protector de la familia.

De otra parte, es conveniente que la denominación del adulto mayor establecida en la Carta Política y que se refiere al «anciano» se actualice a la de adulto mayor, conforme a la denominación establecida en la normativa internacional.

Ahora bien, esta insuficiente normativa de la Constitución viene siendo cubierta en algunos casos por los pronunciamientos del Poder Judicial y del Tribunal Constitucional, casi operando como legislador; así tenemos el conocido caso de María Chura Arcata ${ }^{15}$ que mereció pronunciamiento tuitivo mediante proceso de Amparo que definió que el adulto mayor tiene derecho a ser sujeto de crédito y que su denegación por razón de su edad-constituía una práctica discriminatoria, y de esa forma se protegía el derecho a la igualdad y a la no discriminación del adulto mayor. Lo interesante de este caso es que posteriormente el Congreso de la República aprobó el instrumento financiero llamado hipoteca inversa mediante Ley $\mathrm{N}^{\circ}$ $30741^{16}$ que posibilita el acceso al cré- dito al adulto mayor con garantía de un bien inmueble.

A partir de los pronunciamientos jurisdiccionales se ha avanzado bastante en la protección del adulto mayor, pero en cuestiones muy específicas como el derecho pensionario, protección contra la violencia familiar, acceso a la justicia, sin embargo aún resultan avances parciales e insuficientes, y éstos deben darse en la dimensión legislativa propiamente, en las políticas públicas y no en la jurisdiccional como ámbito natural. Podríamos pensar, por ejemplo, en implementar salarios familiares para aquellos que tengan a algún anciano a su cargo, como ocurre en Holanda y Suecia, o en la alternativa de excepción de impuestos por cada anciano que esté a cargo del grupo familiar, como ocurre en España. (Armijo, 2009, p. 398)

Sobre esto último, siempre existirá la dificultad del presupuesto público que en muchos países no destina recursos suficientes para la atención preferente del adulto mayor. Todavía en el Perú, miles de jubilados y cesantes vienen esperando la programación para recibir el pago de beneficios laborales or-

\footnotetext{
14 Artículo 80 de la Constitución de la República Bolivariana de Venezuela. «El Estado garantizará a los ancianos y ancianas el pleno ejercicio de sus derechos y garantías. El Estado, con la participación solidaria de las familias y la sociedad, está obligado a respetar su dignidad humana, su autonomía y les garantiza atención integral y los beneficios de la seguridad social que eleven y aseguren su calidad de vida».

15 María Chura Arcata, adulta mayor de 85 años de edad solicitó al Banco de la Nación un crédito, el cual fue denegado atendiendo a su edad y al denominado riesgo crediticio.

16 La Ley $N^{\circ} 30741$ fue publicada el 28 de marzo del 2018 y posibilita el acceso al crédito de la persona adulta mayor dando en garantía un bien inmueble, la deuda será recién exigible a su fallecimiento.
} 
denados judicialmente, pago que encarna la denominada deuda social que debe merecer una priorización en los compromisos asumidos por el Estado.

\section{c) El Código Civil.}

Este cuerpo normativo, por su parte, no desarrolla normas significativas sobre la persona adulta mayor, en el Libro de personas no se hace alusión alguna, y en el Libro de Derecho de Familia se alude al adulto mayor a través de la institución de los alimentos cuando se determina la obligación alimentaria para los ascendientes. También la regulación venía cuando se regulaba sobre la institución de la curatela; sin embargo con la modificación que sufrió esta institución vía el Decreto Legislativo $\mathrm{N}^{\circ} 1384^{17}$ la causal referida al deterioro mental que constituye impedimento para expresar libremente la voluntad (que en muchos casos se genera por el proceso de envejecimiento o por patologías como la demencia senil o el Alzheimer) fue derogada y con ello la posibilidad que una declaración de interdicción civil posibilite que un adulto mayor reciba a través de la curatela protección de su persona y de sus bienes.

Del análisis sistemático del Código Civil podemos apreciar que la curatela es una institución de derecho familiar cuyo fin radica en el cuidado de la persona y bienes de los mayores de edad incapaces, es decir tiene por objetivo encargar a una persona para que proteja al incapaz y logre su recuperación de la causa que motivó su incapacidad. Es decir que la curatela protege al adulto, en general, (no específicamente al adulto mayor) que se encuentra incapacitado por causales expresas contenidas en la ley y no necesariamente por el proceso natural del envejecimiento.

Las ayudas y salvaguardias, incorporadas a la legislación civil vía el Decreto Legislativo $\mathrm{N}^{\circ} 1384$, pueden convertirse en instituciones útiles para la protección del adulto mayor, pues eliminada la figura del «curador», ${ }^{18}$ estas las reemplazan, permitiendo que el adulto con capacidad restringida pueda ejercer por sí mismo sus derechos.

No obstante lo antes señalado resultaría sumamente importante que para el caso del adulto mayor se hayan instituido ayudas y salvaguardias específicas, que surjan de su propia condición de desvalimiento por el inexorable paso de los años. Pues es cierto que conforme envejecemos, nuestros derechos constitucionales tienen fecha de caducidad. (Armijo, 2009, p. 388) Una necesaria

El Decreto Legislativo $N^{\circ} 1384$ vigente desde el 5 de setiembre del 2018 modifica varios artículos del Código Civil referidos a la capacidad de las personas.

18 El curador es una persona, familiar o no, de la persona declarada interdicta civilmente encargada del cuidado de la persona y sus bienes.

72 Revista Derecho - 5 (2019) 
especificidad de las ayudas y salvaguardias para los adultos mayores contribuiría a la evidente necesidad de protección que se requiere. Pues el sistema de apoyo reconoce y respeta los derechos, la voluntad y las preferencias de las personas con discapacidad, por lo cual es diverso y debe ajustarse a las necesidades específicas de cada individuo. ${ }^{19}$ Tanto más que el propio Tribunal Constitucional afirma que los ancianos se convierten, dentro de la política estatal de salvaguardia a los más desprotegidos, en uno de los grupos de titulares superreforzados de derechos fundamentales. O, como también puede ser, titulares con una calidad especial. ${ }^{20}$

De lo antes señalado se hace evidente que el Código Civil no contiene normas de protección del adulto mayor que pueda ser de necesario complemento al mandato constitucional de protección del anciano en estado de abandono.

\section{d) La ley de la persona adulta mayor $\mathrm{N}^{\circ} 30490$.}

La ley, no constituye el primer cuerpo normativo que tuvo Perú para proteger al adulto mayor, le precede la ley $\mathrm{N}^{\circ} 28803^{21}$ la que tuvo un periodo de vigencia mayor a los diez años. El balance de la indicada ley no resultó enteramente positivo, sin embargo fue el primer esfuerzo serió en contar con una legislación tuitiva de las personas adultas mayores.

La Ley $\mathrm{N}^{\circ} 30490^{22}$ gira en torno a dos ejes, la promoción y la protección de los derechos de las personas adultas mayores, y los objetivos que persigue son establecer un marco normativo que garantice el ejercicio de los derechos del adulto mayor, a fin de mejorar su calidad de vida y su plena integración al desarrollo social, económico, político y cultural de la nación ${ }^{23}$. Compromete la acción del Estado, sociedad y la familia en la protección del adulto mayor, grupo especialmente sensible a la discriminación dada la desvalorización de la que son objeto por parte de la sociedad y el poco interés que en la agenda nacional se le otorga. (Romero, 2005, p. 57)

En ese contexto resulta relevante la determinación del rol de la familia en la protección del adulto mayor, pues en la lógica del mercado, al constituir el adulto mayor un ser «improductivo» en realidad era la familia el único bastión tuitivo, y reducto natural de acogimiento. La sociedad y el Estado asumían preocupación sobre el tema pero desde una

\footnotetext{
Artículo 659-C del Código Civil.

STC 07873-2006-AC, Fundamento Jurídico 5. Caso Félix Tueros.

1 La Ley $\mathrm{N}^{\circ} 28803$ Ley de las personas adulto mayores fue promulgada por insistencia del Congreso de la República en fecha 16 de marzo del 2006.

22 La Ley de la persona adulta mayor fue publicada en el Diario Oficial El Peruano en fecha 21 de julio del 2016.

23. Artículo 1 de la Ley $\mathrm{N}^{\circ} 30490$
} 
dimensión evidentemente declarativa y sesgada. Al respecto recuerdo que una tarde, hace 15 años atrás, pusieron a disposición del Juzgado de Familia a una persona adulta mayor en presunto estado de abandono. La Constitución lo protege (conforme a la norma contenida en el artículo 4), sin embargo la norma carecía a su vez de una norma de desarrollo constitucional, por lo tanto, el caso se presentaba como no judicializable en la medida de la inexistencia de una norma que desarrolle un procedimiento concreto de protección. Por lo tanto, el mismo tuvo que transitar por un trámite administrativo a través de la gestión de la Beneficencia Pública, y la única medida de protección a dictarse fue la del albergamiento, sin posibilidad de iniciar una investigación para determinar las razones que determinaron la situación dramática del adulto mayor. La investigación que se debería de haber realizado era una muy similar a aquella efectuada a los niños, niñas o adolescentes en presunto estado de abandono (hoy desprotección familiar), y ésta investigación sobre todo debería de iniciarse en el seno familiar.

La Ley, impone deberes a la familia nuclear y la extensa en el cuidado del adulto mayor, ${ }^{24}$ y ello es un aporte muy valioso, pues en tiempos de indolencia e insensibilidad de algunos miembros de la familia es necesario positivisar mandatos que se fundan mayormente en la socioafectividad y el imperativo moral. Sin embargo, se aprecia que la ley no articula mecanismos coercitivos para garantizar el cumplimiento de dichos mandatos, cómo si lo hace cuando las instituciones de la sociedad civil y del propio Estado no cumplen los imperativos contenidos en la ley, mediante los procedimientos sancionadores correspondientes. En ese sentido, la ley presenta un vacío.

Frente a ello es necesario precisar que paralelamente se encuentran vigentes otras normas que pueden posibilitar imperativos para brindar la protección esperada. Así, la Ley $\mathrm{N}^{\circ} 30364$, que reprime la violencia contra los integrantes del grupo familiar, entre las que se encuentran las personas adultas mayores, contempla interesantes mecanismos de protección. La ley referida protege tanto contra la violencia producida por conductas activas, como también por conductas omisivas. Así, el estado de abandono o desprotección familiar en que son sumidos los adultos mayores por sus propios familiares puede ser considerada como violencia psicológica o patrimonial, ${ }^{25} \mathrm{y}$ en tal medida puede generar la necesidad de dictar medidas de

$24 \quad$ Artículo 7 de la Ley $N^{\circ}$ 30490. Deberes de la Familia: a) Velar por su integridad física, mental y emocional; b) Satisfacer sus necesidades básicas de salud, vivienda, alimentación, recreación y seguridad. c) Visitarlo periódicamente. d) Brindarle los cuidados que requiera de acuerdo a sus necesidades.

25 La Ley considera violencia patrimonial a la «Pérdida, sustracción, destrucción, retención, apropiación de objetos, documentos, bienes, no dar recursos económicos para necesidades básicas».

74 Revista Derecho-5 (2019) 
protección a su favor, como por ejemplo la asignación provisional de una pensión de alimentos o la obligación de atender las necesidades del adulto mayor por parte de sus familiares directos. Tales medidas de protección deben ejecutarse en forma obligatoria por provenir de mandatos judiciales.

No obstante, la ley del adulto mayor establece que el Estado promueve el fortalecimiento de la protección de la persona adulta mayor por parte de la familia. Este mandato es importante y completa en ese sentido la omisión del texto constitucional por cuanto la familia es la instancia donde se encuentran quienes le pueden brindar ayuda que pudiera necesitar y ser fuente de apoyo afectivo tan necesario para asumir las pérdidas que conlleva el envejecer (Placeres, y De Leon, 2019). A lo largo del tiempo la institución familiar sólo se encontraba vinculada a la situación del adulto mayor mediante los vínculos socioafectivos, esperando en forma natural y espontánea que la familia o alguno de sus integrantes asuma el cuidado y protección del adulto mayor en el seno familiar. Sin embargo la realidad nos ofrece un escenario a menudo cruel, pues muchos adultos mayores son relegados, discriminados, maltratados y hasta abandonados. La ley debería de disponer que los integrantes del grupo familiar, específicamente los hijos asuman la responsabilidad de encargarse de los padres adultos mayores bajo el principio de reciprocidad. Así, en el caso de incumplimiento de dicha obligación la ley igualmente debe disponer mecanismos de coerción y de sanción.

En ese contexto no resulta irreal ni exagerado la propuesta de extender los efectos tuitivos de la tutela a la protección de la persona del adulto mayor, bajo el principio de reciprocidad, es decir, que los padres adultos mayores no necesiten encontrarse en estado de abandono o de discapacidad para que los hijos mayores de edad asuman su cuidado. Pues se ha estimado que la incapacitación no debe afectar el ejercicio de derechos fundamentales (Barranco, 2012), como el de respeto a su dignidad como persona, lo que habilita a un adulto mayor a recibir protección de su nucleo familiar y ello debe significar una obligación para los hijos mayores de edad. Tal posibilidad además se enmarca en lo dispuesto en el artículo 5.1. de la Ley, acapites $\mathrm{d} y \mathrm{e}$, recibir cuidado y protección familiar y vivir en familia y envejecer en el hogar. Asimismo lo dispuesto en el artículo 7 que impone a los hijos el deber de velar por su integridad, satisfacer sus necesidades y brindarle los cuidados que requiera.

Por lo expuesto entonces se aprecia que existen las condiciones, tanto en el marco constitucional como legal para que extender los alcances de la tutela como institución jurídica que brinde protección específica e integral a los adultos mayores, lo que haría de la tutela la institución adecuada para su protección

Revista Derecho - 5 (2019) 75 
y de esa forma hacer del envejecimiento un proceso digno.

\section{CONCLUSIONES.}

Que se ha demostrado que el envejecimiento de la población es un proceso inexorable de carácter ascendente y que nos proyecta una visión de incremento de la población de adultos mayores, y que tanto en el contexto internacional como nacional, la situación social del adulto mayor se presenta como dramática en razón de que no se le brinda la promoción y protección correspondiente, permitiendo que éste se ubique no solamente en situaciones de alto riesgo, discriminación, y de abandono moral y material.

Que la problemática social del adulto mayor esta ligado a que su consideración jurídica lo ubica como un adulto más, al que no se le brinda tratamiento especial fruto del declive de sus capacidades físico mentales, y si bien recibe un tratamiento constitucional, al establecerse el principio de que el anciano en estado de abandono recibe una protección especial de parte de la comunidad y del Estado, sin embargo esta protección no se extiende a toda situación en que éste se encuentre.

La legislación infraconstitucional si bien compromete la acción de la familia, no completa el vacío constitucional pues la protección del adulto mayor se circunscribe a los aspectos referidos al sistema previsional, a la protección frente a la violencia familiar, y a la atención preferente en la prestación de servicios, pero no lo protege frente a la desprotección material como afectiva.

Es necesario extender los alcances de la institución jurídica de la tutela para comprometer la acción de los hijos mayores de edad, para que bajo el principio de reciprocidad se encarguen del cuidado de los padres (adultos mayores) en forma obligatoria, sin que necesariamente estos se encuentren con alguna discapacidad

\section{REFERENCIAS BIBLIOGRÁFICAS.}

Armijo, G. (2009). Poder Económico y discriminación etaria: la tutela del adulto mayor como derecho humano emergente. Anuario de Derecho Constitucional Latinoamericano Año XV, 387-404.

Barcia Lehmann, R. (2014). Algunas críticas al derecho común y especialmente a la regulacipón de las incapacidades respecto del adulto mayor en el ordenamniento jurídico chileno. Revista Chilena de Derecho Privado, 57-86.

76 Revista Derecho-5 (2019) 
Belsky, J. (1996). Psicologia del envejecimiento. Madrid: Editorial Paraninfo.

Dueñas Ruiz, O. (2009). Adulto mayor, políticas públicas y servicios sociales en Bogotá. Reflexión Politica Año $11 N^{\circ}$ 21, 133144.

Gonzales Mantilla, G. (1996). La consideración jurídica del embrión in vitro. Lima: Fondo Editorial de la Pontificia Universidad Católica del Perú .

INEI. (2018). Informe Técnico situación de la población adulta mayor juliosetiembre 2018 . Lima: INEI.

Maria, B. (2012). Capacidad jurídica y discapacidad: el artículo 12 de la convencion de derechos de las personas con discapcidad. Anuario Facultad de Derecho, 353-356.

Montoya, Victor Hugo y Feijoo, Raúl. (2015). El Rango de los Tratados en Derechos Humanos. Revista Ius Et Veritas Vol. 50, 314-342.

Mora Jimenez, M. (2010). Existe protección real a los Derechos Humanos del Adulto Mayor? El Discurso Legal. Revista de Ciencias Sociales, 126134.
OMS. (10 de mayo de 2019). Organizacion Mundial de la Salud. Obtenido de https:/ /www.who.int/es/newsroom/fact-sheets/detail/ envejecimiento-y-salud

Placeres, Jose y De Leon, José. (29 de mayo de 2019). Revista Médica Electrónica. Obtenido de http://scielo.sld.cu/ scielo.php? s cript =sci_arttext\&pid=S168418242011000400010

Romero, J. (2005). Discriminación y adultos mayores: un problema mayor. Tiempo económico, 56-63.

Rubio Correa, M. (2001). El ser bumano como persona natural. Lima: Fondo Editorial Pontificia Universidad Católica del Perú.

Ruiz Miguel, A. (1988). El principio de jereraquía normativa. Revista española de Derecho Constitucional, 135-154.

Varsi Rospigliosi, E. (2014). Tratado de Derecho de las Personas. Lima: Gaceta | Jurídica.

Zapata Farias, H. (2001). Adulto mayor: participación e identidad. Revista de Psicología d ela Universidad de Chile. Vol. X $N^{\circ} 01,190$.

Revista Derecho - 5 (2019) 77 
78 Revista Derecho-5 (2019) 